\title{
Pembelajaran IPA Terintegrasi Al-Quran dan Nilai-Nilai Pesantren
}

\author{
Muhammad Mujahidus Shofa ${ }^{1}$, Lin Eflina Nailufa ${ }^{2}$, Arghob Khofya Haqiqi ${ }^{3}$ \\ 1,2,3 Program Studi Tadris IPA, Institut Agama Islam Negeri Kudus, Indonesia \\ , Jl. Conge Ngembal Rejo, Bae, Kudus, Jawa Tengah \\ Coressponding Author E-mail: \\ 1 mujahidusshofa99@gmail.com \\ 2 aannailufa@gmail.com \\ 3 arghobhaqiqi@gmail.com
}

\begin{abstract}
Abstrak
Santri pada dasarnya mempelajari agama secara mendalam dan kurang menyukai pembelajaran IPA karena adanya dikotomi antara ilmu umum dan ilmu agama, padahal semua ilmu itu bersumber dari Al-Quran. Ada lebih dari 800 ayat kauniyyah Al-Quran namun pembahasan tentang itu kurang diminati. Penelitian ini bertujuan mendesain pembelajaran IPA terintegrasi Al-Quran dan nilai-nilai pesantren serta bagaimana implementasinya. Kajian ini menggunakan pendekatan kualitatif dengan jenis studi pustaka (library research) untuk menganalisis Kompetensi Inti dan Kompetensi Dasar IPA Terpadu yang ada di SMP/MTs Kelas VII, ayat-ayat Al-Qur'an yang berisi ayat kauniyah serta nilai-nilai pesantren. Hasil menunjukkan semua Kompetensi Inti dan Kompetensi Dasar memiliki potensi pengintegrasian pembelajaran IPA dengan AlQuran dan nilai-nilai pesantren. Hal ini dapat dijadikan sebagai kerangka awal islamisasi sains dalam bidang pendidikan.
\end{abstract}

Kata kunci: Pembelajaran IPA; Integrasi Al-Quran; Nilai-Nilai Pesantren

\begin{abstract}
Santri basically studied religion deeply and did not like science learning because of the dichotomy between general science and religious sciences, even though all the knowledge came from the Quran. There are more than 800 verses of the Kauniyyah of the Quran, but the discussion about them is of little interest. This study aims to design integrated Quran science learning and Pesantren values and how they are implemented. This study uses a qualitative approach with the type of library research to analyze the Core Competencies and Basic Competencies of Integrated Science in VII Class SMP / MTs, verses of the Quran which contain verses of kauniyah and the values of pesantren. The results show that all Core Competencies and Basic Competencies have the potential to integrate science learning with the Quran and pesantren values. This can be used as an initial framework. for the Islamization of science in the field of education.
\end{abstract}

Keywords: Science Learning; Qur'an Integration; Pesantren Values

How to cite this article :

Shofa, M. M., Nailufa, L. E., \& Haqiqi, A. K. (2020). Pembelajaran IPA Terintegrasi Al-Quran dan Nilai-Nilai Pesantren. IJIS Edu : Indonesian Journal of Integrated Science Education, 2(1), 81-90. doi:http://dx.doi.org/10.29300/ijisedu.v2i1.1928 


\section{PENDAHULUAN}

Pendidikan memiliki peran yang besar dalam penyediaan sumber daya manusia yang berkualitas dan berdaya saing tinggi. Proses pengembangan kualitas sumber daya manusia merupakan salah satu bentuk perubahan sosial. Semakin tinggi pendidikan seseorang maka semakin tinggi peluang untuk meningkatkan kualitas daya saing. Di Indonesia dikenal ada beberapa model pendidikan di antaranya adalah model pondok pesantren dan model pendidikan sekolah (Nurochim, 2016)

Pesantren merupakan salah satu pendidikan yang ada di indonesia. Sistem pendidikan yang menitikberatkan pada pemahaman secara menyeluruh dan kesiapan terjun di masyarakat. Dalam Peraturan Menteri Agama Nomor 13 Tahun 2014 pasal 2, tentang Pendidikan Keagamaan Islam bahwa penyelenggaraan pendidikan pesantren sebagai bagian pendidikan keagamaan Islam bertujuan untuk: (a) menanamkan kepada peserta didik untuk memiliki keimanan dan ketaqwaan kepada Allah Swt., (b) mengembangkan kemampuan, pengetahuan, sikap dan keterampilan peserta didik untuk menjadi ahli ilmu agama Islam (mutafaqqih fi al-din), dan (c) mengembangkan pribadi akhlak al-karimah bagi peserta didik yang memiliki kesalehan individual dan sosial dengan menjunjung tinggi jiwa keikhlasan, kesederhanaan, kemandirian, persaudaraan sesama umat Islam, rendah hati, toleran, keseimbangan, moderat, keteladanan, pola hidup sehat, dan cinta tanah air.

Institusi pendidikan pesantren dan institusi pendidikan sekolah memiliki sistem sosial dan keunggulan masing-masing. Untuk itu cara mengakomodasi dikotomi antara institusi pendidikan pesantren dan institusi pendidikan sekolah yaitu dengan model Sekolah Berbasis Pesantren. Sekolah Berbasis Pesantren, yakni program yang berupaya mengintegrasikan keunggulan sistem pendidikan sekolah dengan penyelenggaraan pendidikan di pondok pesantren (Nurochim, 2016).

Pesantren merupakan institusi pendidikan yang selain mempunyai corak indigenous (keaslian) Indonesia, juga mempunyai corak keislaman. Latar belakang kemunculan pesantren adalah untuk mentransmisikan produk pemikiran skolastik Islam tradisional. Ini berarti pesantren secara genealogis terikat kuat dengan budaya dan tradisi pemikiran Islam abad pertengahan. Pada abad tersebut, pendidikan Islam secara garis besar berkembang dalam dua aliran, yaitu konservatif dan rasional. Pendidikan Islam konservatif yang telah memenangkan percaturan pada waktu itu, secara tidak langsung berpengaruh besar terhadap model dan pelaksanaan pendidikan Islam di era sekarang, termasuk di Indonesia. Bahkan hingga kini masih kuat anggapan dalam masyarakat luas yang mengatakan bahwa "agama"dan "ilmu" adalah dua entitas yang tidak dapat dipertemukan. Pandangan dualisme-dikotomis keilmuan yang seperti itu haruslah di koreksi dan diluruskan, dengan konsep yang lebih mampu mendialogkan dan mengintegrasikan antara agama dan ilmu pengetahuan umum lainnya (Yusuf, 2015).

Madrasah yang merupakan lini pendidikan formal pada kebanyakan pesantren menjadi ladang integerasi ini. Materi pembelajaran di Madrasah lebih mengutamakan pada pembekalan kemampuan yang fungsional untuk kehidupan dalam berbagai bidang dengan basis pada nilai-nilai ajaran Islam. Ilmu Pengetahuan Alam (IPA) merupakan salah satu mata pelajaran yang wajib diterima oleh siswa. Pemberian mata pelajaran IPA memiliki tujuan agar siswa memperoleh kompetensi ilmu pengetahuan dan teknologi serta membudayakan berpikir ilmiah, kreatif dan mandiri.

Hakikat IPA merupakan gelaja-gejala alam pada dimensi pengetahuan (keilmuan), dengan begitu, pengetahuan dapat dikaitkan pada dimensi nilai ukhrawi, dimana dengan memperhatikan keteraturan di alam semesta akan semakin meningkatkan keyakinan akan adanya sebuah kekuatan yang Maha dahsyat yang tidak dapat dibantah lagi, yaitu Allah SWT. Dimensi ini menggambarkan hakikat IPA adalah memautkan antara aspek logika-materil dengan aspek spiritual, yang sementara ini dianggap cakrawala kosong, karena suatu anggapan antara IPA dan agama merupakan dua sisi yang berbeda dan tidak mungkin dipersatukan satu sama lain dalam satu bidang kajian. Pada kenyataannya terdapat benang merah ketertautan di antara keduanya.(Latifah \& Ratnasari, 2016)

Al-Quran adalah kitab suci yang berdimensi banyak dan berwawasan luas ditambah lagi isyaratisyarat ilmiahnya yang sungguh mengagumkan ilmuwan masa kini. Al-Quran juga berperan utama dalam konteks perkembangan sains, khususnya sains Islam. Al-Quran membuktikan diri sebagai mukjizat yang komprehensif karena ia tetap relevan dengan perkembangan mutakhir yang dicapai umat manusia di era ilmu dan nalar. Sebuah era baru yang melampaui segala sesuatu yang bersifat material dan fisikal, dan memberikan perhatian besar pada aspek pemikiran dan nalar, sebab ia merupakan pilar utama yang menjadi pondasi seluruh kehidupan manusia.

Al-Quran merupakan sumber dari segala sumber ilmu pengetahuan tampaknya sudah tidak 
asing lagi di telinga kita. Bahkan hampir semua ilmu pengetahuan yang muncul di permukaan saat ini telah termuat di dalam kitab suci Al-Quran, walaupun tidak dijelaskan secara rinci. Al-Quran turun sejak 14 abad silam sebagai wahyu ilahi yang mampu menembus batas-batas metafisika dan futuristic (berhubungan dengan masa yang akan datang). Dalam kerangka pikir modern, Ilmu dan Agama bagaikan minyak dan air, walaupun keduanya masing-masing mempunyai sudut pandang yang berbeda. Oleh sebab itulah meskipun Al-Quran pada asasnya adalah kitab keagamaan, namun kajian-kajian dan kandungan isinya tidak terbatas pada bidang-bidang keagamaan saja. Ia juga meliputi berbagai aspek kehidupan manusia seperti ilmu sains (Arifuddin, 2015; Sudiarti, Delilah, \& Aziz, 2018).

Pembelajaran pada kurikulum 2013 menekankan pada aspek pendidikan karakter. Tujuan dari kurikulum 2013 terdiri empat cakupan kompetensi, yaitu (1) kompetensi sikap spiritual, (2) kompetensi sikap sosial, (3) pengetahuan, dan (4) keterampilan. Hal tersebut dicapai dari proses pembelajaran intrakurikuler, kokurikuler, atau ekstrakurikuler. Itulah isi dari cakupan yang ada di pedoman Badan Penelitian dan Pengembangan tahun 2013 (Alimuddin, 2014). Penumbuhan dan pengembangan kompetensi sikap dilakukan sepanjang proses pembelajaran berlangsung dan dapat digunakan sebagai pertimbangan guru dalam mengembangkan karakter peserta didik lebih lanjut.

Rumusan Kompetensi Sikap Spiritual yaitu "Menghargai dan menghayati ajaran agama yang dianutnya". Rumusan Sikap Sosial yaitu "Berperilaku jujur, disiplin, memiliki rasa tanggung jawab, peduli (toleransi dan gotong royong), santun, dan percaya diri, dalam berinteraksi secara efektif dengan lingkungan sosial dan alam dalam jangkauan pergaulan dan keberadaannya". Kedua kompetensi tersebut dicapai melalui pembelajaran tidak langsung (indirect teaching), yaitu keteladanan, pembiasaan, dan budaya sekolah dengan memperhatikan karakteristik mata pelajaran serta kebutuhan dan kondisi peserta didik (Hudson, 2015; H. Jung \& Choi, 2016; Y. Jung \& Lee, 2018; Mengel, Sauermann, \& Zölitz, 2019; Skaalvik \& Skaalvik, 2011; Wong, Ruble, Yu, \& McGrew, 2017).

Hal ini sesuai dengan tujuan dan nilai-nilai yang ada didalam pesantren. Nilai dasar dalam pesantren menjadikan santri sebagai insan "Shalibakram". Istilah shalih ini diambil dari surah alAnbiya ayat 105: '... anna al ardl yaritsuba ibadiya as shalibuun...' Menurut pendapat Mahfudh (2007), shalih adalah sosok manusia ideal yang secara potensial mampu berperan aktif, berguna dan terampil dalam kehidupan sesama makhluk untuk mencetak manusia yang berguna terhadap sesamanya dengan berbekal ilmu pengetahuan dari pesantren yang berkaitan dengan kebutuhan kehidupan.

Sedangkan akram pada dasarnya diambil dari ayat 'Inna akramakum 'inda Allabi atqaakum' (AlHujuraat, 13) yang dipahami sebagai bentuk ideal seorang muslim dengan kesalehan transendental dalam hubungannya sebagai individu dengan Allah Sang Pencipta. Karakter akram dipersonifikasikan melalui niat yang baik, keikhlasan dan menjadikan motivasi seluruh aktifitas hidupnya hanya kepada Allah sehingga dalam tahap puncaknya merupakan pencapaian kelebihan manusia sebagai makhluk terhadap Khaliqnya demi mencapai kebahagiaan di akhirat (Mahfudh, 2007).

Dari uraian diatas perlu adanya pengembangan model pembelajaran yang memuat pengintegrasian antara Pembelajaran IPA, AlQuran, dan nilai-nilai Pesantren untuk membentuk generasi yag tidak hanya pintar secara akademik (kognitif) tapi juga secara sikap dan spriritual agar tercapai pendidikan yang optimal.

\section{METODE}

Kajian ini menggunakan pendekatan kualitatif dengan jenis studi pustaka (library research). Pendekatan kualitatif merupakan prosedur yang menghasilkan data deskriptif berupa kata-kata (ucapan), tulisan, dan perilaku dari orang-orang yang dapat diamati (Hsieh \& Shannon, 2005; Maxwell \& Reybold, 2015; Parker \& Parker, 2020; Qu \& Dumay, 2011; Williamson, Given, \& Scifleet, 2018). Pendekatan kualitatif ini juga dilakukan oleh penelitian yang dilakukan oleh Novitasari, Nasirun, \& D., (2019); Selviani, (2019); Sudarsana, (2018); Tiswarni, (2019). Pendekatan ini digunakan untuk mendesain pembelajaran IPA terintegrasi AlQur'an dan nilai-nilai pesantren dengan menganalisis dokumen-dokumen terkait dengan kurikulum IPA Terpadu yang ada di SMP/MTs yang diterbitkan oleh Kementerian Pendidikan dan Kebudayaan tahun 2013, ayat-ayat Al-Qur'an yang berisi ayat kauniyah serta nilai-nilai pesantren dan implementasi kurikulumnya. Sesuai dengan jenis sumber data yang bertumpu pada data dokumenter, maka pengumpulan data dalam studi ini menggunakan metode dokumentasi. Analisis data dilakukan dengan menggunakan metode analisis dokumen (document analysis). Hasil desain yang dibuat diverifikasi melalui analisis konten dan kesesuainnya dengan Kurikulum Nasional jenjang SMP/MTs pada mata pelajaran IPA khususnya 
pada kelas VII sebagai konsentrasi pada penelitian kali ini.

\section{HASIL DAN PEMBAHASAN}

Dalam Ayat-Ayat Semesta Khoirudin (2017) menjelaskan terdapat 800 ayat Al-Quran yang termasuk ayat kauniyyah, namun perhatian ulama tidak banyak yang mengkajinya dibandigkan dengan ayat hukum yang jumlahnya hanya seperlima dari ayat kauniyyah.

Dengan menganalisi struktur kurikulum berupa Kompetensi Dasar mata pelajaran IPA Terpadu Kelas VII SMP/ MTs terdapat kesesuain antara materi pokok pada KD dengan ayat-ayat kauniyyah tersebut sebagaimana tabel 1 .

Tabel 1 Analisis Kompetensi Dasar (KD) IPA kelas VII SMP/MTs dan potensi integrasi dengan Ayat Al-Quran

\begin{tabular}{|c|c|c|}
\hline Kode & Kompetensi Dasar & Ayat Al-Quran \\
\hline 3.1 & $\begin{array}{l}\text { Menerapkan konsep pengukuran berbagai } \\
\text { besaran dengan menggunakan satuan standar } \\
\text { (baku) }\end{array}$ & $\begin{array}{l}\text { QS. al-An'am: 152; QS. al-A'raf: } \\
\text { 85; QS. Al-Syura:17; QS. Al-Hijr: 21; } \\
\text { QS. Al-Huud: 84-85; Q.S Ar-Rahmaan: } \\
\text { 8-9 }\end{array}$ \\
\hline 3.2 & $\begin{array}{l}\text { Mengklasifikasikan makhluk hidup dan } \\
\text { benda berdasarkan karakteristik yang diamati }\end{array}$ & $\begin{array}{l}\text { QS. Al-Fushilat: 53; QS. Al- } \\
\text { thahaa: 53; QS.Al-An'am: 38; Q.S Al- } \\
\text { Baqarah : ayat 31-33; QS. Asy-Syu'ara' : } \\
7\end{array}$ \\
\hline 3.3 & $\begin{array}{l}\text { Menjelaskan konsep campuran dan zat } \\
\text { tunggal (unsur dan senyawa), sifat fisika dan kimia, } \\
\text { perubahan fisika dan kimia dalam kehidupan } \\
\text { sehari-hari }\end{array}$ & $\begin{array}{l}\text { Q.S Yunus: 61; QS. Al-Baqarah: } \\
\text { 74; QS. Al-A'raf: 58;QS. Al-imran: 190; } \\
\text { QS. Ar-Raad: 15; QS. Al-Insyiqaq: 16- } \\
\text { 19 }\end{array}$ \\
\hline 3.4 & $\begin{array}{l}\text { Menganalisis konsep suhu, pemuaian, kalor, } \\
\text { perpindahan kalor, dan penerapannya dalam } \\
\text { kehidupan sehari-hari termasuk mekanisme } \\
\text { menjaga kestabilan suhu tubuh pada manusia dan } \\
\text { hewan }\end{array}$ & Q.S Al-Fatir: 21; QS. An-Nahl: \\
\hline 3.5 & $\begin{array}{l}\text { Menganalisis konsep energi, berbagai } \\
\text { sumber energi, dan perubahan bentuk energi dalam } \\
\text { kehidupan sehari-hari termasuk fotosintesis }\end{array}$ & $\begin{array}{l}\text { QS. Ar-Raad: 4; QS. Al-Waqiah: } \\
\text { 71-73; QS. Yasin: 80: ; QS. Thaha: 10; } \\
\text { QS. al-Naml:7 }\end{array}$ \\
\hline 3.6 & $\begin{array}{l}\text { Mengidentifikasi sistem } \\
\text { kehidupan mulai dari tingkat sel sampai organisasi } \\
\text { dan komposisi utama penyusun sel }\end{array}$ & QS. Al-Furqan: 2 ; QS. Al 'Alaq: \\
\hline 3.7 & $\begin{array}{l}\text { Menganalisis interaksi antara makhluk hidup } \\
\text { dan lingkungannya serta dinamika populasi akibat } \\
\text { interaksi tersebut }\end{array}$ & $\begin{array}{l}\text { QS. Al-Baqarah : } 164 \text {; QS. Al- } \\
\text { Hujarat: } 13\end{array}$ \\
\hline 3.8 & $\begin{array}{c}\text { Menganalisis } \\
\text { terjadinya } \\
\text { lingkungan dan dampaknya bagi ekosistem }\end{array}$ & $\begin{array}{l}\text { QS. Saba': 15-16; QS. Ar-rum: } 41 \\
\text {; QS. Al-Qashash : } 77 \text { QS. Al Syuara' } \\
\text { :183 }\end{array}$ \\
\hline 3.9 & $\begin{array}{ccc}\text { Menganalisis perubahan } & \text { iklim } & \text { dan } \\
\text { dampaknya bagi ekosistem } & & \\
\end{array}$ & QS. Ar-rum: 41; QS. Al-Thur: 44 \\
\hline 3.10 & $\begin{array}{l}\text { Menjelaskan lapisan bumi, gunung api, } \\
\text { gempa bumi, dan tindakan pengurangan resiko } \\
\text { sebelum, pada saat, dan pasca bencana sesuai } \\
\text { ancaman bencana di daerahnya }\end{array}$ & QS. Al-Thalaq: 12 \\
\hline 3.11 & $\begin{array}{l}\text { Menganalisis sistem tata surya, rotasi dan } \\
\text { revolusi bumi, rotasi dan revolusi bulan, serta } \\
\text { dampaknya bagi kehidupan di bumi }\end{array}$ & $\begin{array}{l}\text { QS. Adz-Dzariyat: } 7 \text {; QS. Al- } \\
\text { Anbiya': } 33 \text {; Yasin: } 40 \text { QS.Yasin: } 38 \text {; } \\
\text { QS. Shaffat: } 5 \text {; QS. Yunus: } 5 \text { QS. Yasin: } \\
\text { 39; QS.Syams: 1-2 ; QS. Az-Zumar: } 5 \text {; } \\
\text { QS. Al-Naml: } 88\end{array}$ \\
\hline
\end{tabular}

Berdasarkan analisis kompetensi dasar (KD) IPA kelas VII SMP/MTs dan potensi integrasi dengan ayat Al-Quran terdapat ayat-ayat yang sesuai dengan semua KD. Disini terdapat potensi 
yang sangat besar munculnya Pembelajaran IPA terintegrasi Al-Quran dan nilai-nilai pesantren

\section{Kerangka Pengintegrasian Kurikulum}

Dalam tataran konseptual integrasi nilai dalam pembelajaran IPA mengacu kepada pemahaman bahwa Ilmu pengetahuan apapun termasuk ilmu pengetahuan alam adalah sarana menuju Tuhan, jika manusia sejak dini menyadari bahwa kehidupan di dunia menuntutnya untuk pencapaian kehidupan akhirat. Pada akhirnya, segala macam ilmu pengetahuan yang memberikan kebaikan di dunia dan di akhirat itu penting untuk dipelajari. Al-Ghazali menekankan perlunya manusia membuat skala prioritas pendidikan dengan menempatkan ilmu agama dalam posisi terpenting.

Proses pembelajaran pada hakikatnya adalah proses mengamati, menemukan, memahami, dan menghayati sunnatullah, yang berupa fenomena alamiah maupun sosial, kemudian mengaplikasikan pemahaman tersebut bagi kemaslahatan hidup manusia dan lingkungannya serta menjadikan kesadaran adanya Allah dengan sifat-sifat-Nya Yang Maha Sempurna sebagai tujuan hakiki dari kegiatan pembelajaran. Tujuan ini akan membimbing peserta belajar kepada kesadaran adanya realitas supranatural di luar realitas eksternal yang dapat ia indera. Oleh sebab itu, prinsip prinsip dasar kegiatan ilmiah yang digariskan AlQuran, harus dijadikan titik tolak dalam mempelajari subyek apapun (Harahap, 2018; Idrus Hariri \& Mulyani, 2016)

Harahap (2018) menjelaskan hubungan antara Al-Quran dan Sains menjadi 2 hubungan:

1. Konflik, Hubungan ini menempatkan AlQuran dan sains dalam dua sisi yang terpisah dan saling bertentangan. Pandangan ini menyebabkan Al-Quran menjadi terkesan menegasi kebenarankebenaran yang diungkap dunia sains dan sebagainya. Hal ini sebagaimana yang telah dilakukan oleh ilmuwan non Muslim, seperti; - penciptaan manusia yang berasal dari kera kemudian berevolusi menjadi manusia (teori Darwin), sedangkan AlQuran menentang hal itu tepatnya pada surah at-Tìn [95]: 4, yang menjelaskan bahwa; -manusia itu diciptakan sempurna, tanpa ada proses revolusi.

2. Integrasi, Hubungan antara Al-Quran dan sains itu dinyatakan sebagai hubungan integrasi. Dalam hal ini Al-Quran dan sains saling dihubung kaitkan dalam sebuah penelitian, yang mana hal itu ada dalam $\mathrm{Al}-$
Quran. Dengan kata lain Al-Quran sebagai dasar dalam sebuah penelitian yang dilakukan, dan menjadikan Al-Quran sebagai dasar dari penelitian, seperti; AlQuran mengatakan adanya gunung api di dasar laut pada surah At-Thūr [21]: 6 Allah SWT berfirman: -Dan Demi laut, yang di dalam tanahnya ada api. Dalam hal ini tugas sainslah yang mengkaji lebih lanjut dari penyebab.

Barizi (2011) menjelaskan ada beberapa langkah yang dapat dijadikan acuan ke arah pengembangan model integrasi Al-Quran dan sains dalam pendidikan:

Pertama, memetakan konsep ke-Ilmuwan dan ke-Islaman. ilmuwan perlu diajak memahami bersama Al-Quran ke alam ilmu pengetahuan, dengan cara mengklasifikasikan sains secara sistematis ke dalam berbagai disiplin ilmu atau tema-tema yang dikehendaki. Dengan kata lain, ilmuan disarankan terlebih dahulu menjelajahi tema-tema sains yang ada di dalam Al-Quran.

Kedua, memadukan konsep keilmuan dan keislaman. Kerja ini, mengintegrasikan konsep, bukan rumus-rumus. Yaitu mencari titik kesamaan antara Al-Quran dan sains. Tegasnya, antara AlQuran dan sains diintegrasikan sehingga satu sama lain saling memperkokoh dalam membuka tabir kegaiban akan realitas konkrit yang firmankan Allah SWT dalam ayat-ayat-Nya, baik yang qauliyah maupun kauniyah.

Ketiga, menjadikan Al-Quran sebagai pengawal dari setiap kerja sains. Al-Quran bukan sekedar menjadi pelengkap, tetapi sumber rujukan utama agar supaya menjadi lebih terarah dan mempunyai tujuan yang mengandungi banyak manfaat.

\section{Implementasi dalam Pembelajaran}

Kurikulum 2013 dirancang untuk memperkuat kompetensi siswa dari sisi pengetahuan, keterampilan dan sikap secara utuh. Proses pencapaiannya melalui pembelajaran sejumlah mata pelajaran yang dirangkai sebagai suatu kesatuan yang saling mendukung pencapaian kompetensi tersebut. Bila pada jenjang SD/ MI, semua mata pelajaran digabung menjadi satu dan disajikan dalam bentuk tema-tema, maka pada jenjang SMP/MTs pembelajaran sudah mulai dipisah-pisah menjadi mata pelajaran. Bukti transisi ke dalam pendidikan menengah, pemisahan mata pelajaran ini belum dilakukan sepenuhnya pada jenjang SMP/MTs. Materi-materi dari bidangbidang ilmu Fisika, Kimia, Biologi, dan Ilmu Bumi dan Antariksa masih perlu disajikan sebagai suatu 
kesatuan dalam mata pelajaran IPA (Ilmu Pengetahuan Alam). Hal ini dimaksudkan untuk memberikan wawasan yang utuh bagi siswa SMP/MTs tentang prinsip-prinsip dasar yang mengatur alam semesta beserta segenap isinya. (Kemendikbud, 2017)

Mata pelajaran IPA di SMP/MTs dilakukan dengan konsep integrative science (IPA Terpadu). Konsep keterpaduan ini ditunjukkan pada penyajian materi IPA dikemas ke dalam tema tertentu yang di dalamnya membahas perpaduan materi-materi fisika, kimia, dan biologi, yang saling berkaitan (Kemendikbud, 2017). IPA di SMP/MTs ditinjau dari sudut pandang kajian Biologi sehingga penyajian konsep-konsep IPA pada bahan ajar IPA terpadu di SMP/MTs diawali dengan fenomena biologi yang ada di sekitar peserta didik dan membahasnya dengan tinjauan dari tiga bidang kajian (biologi, fisika, dan kimia). Hal ini bertujuan agar tampak keterpaduan antara tiga bidang kajian tersebut. Meskipun demikian, tetap akan tampak karakter dari tiap-tiap bidang kajian karena bagaimanapun juga terdapat perbedaan yang mendasar antara tiga bidang kajian tersebut. Keterpaduan konsep dalam IPA terpadu tidak berarti membentuk konsep baru dari konsep dasar fisika, kimia, dan biologi, tetapi terpadu dalam objek yang dipelajari.

Implikasi Pembelajaran IPA terintegrasi AlQuran dan nilai-nilai pesantren pada Kelas VII SMP/MTs, melalui tiga tahap seperti yang dijelaskan Barizi (2011) tahap pertama dilakukan dengan analisis konmpetensi dasar dilakukan dengan cara mengklasifikasikan sains secara sistematis ke dalam berbagai disiplin ilmu atau tema-tema yang dikehendaki, kemudian dilakukan pemahaman ayat-ayat kauniyyah dengan tema tersebut. Dengan bantuan tafsir tematik dapat dengan mudah menemukan ayat yang sesuai dan memahaminya dengan baik. Pada tabel 1 dijelaskan analisis Kompetensi Dasar (KD) IPA kelas VII SMP/MTs dan potensi integrasi dengan Ayat AlQuran.

Tahap kedua memadukan konsep keilmuan dan keislaman. Kerja ini, mengintegrasikan konsep, bukan rumus-rumus. Yaitu mencari titik kesamaan antara Al-Quran dan sains. Contoh Kompetensi Dasar 3.11 yaitu Menganalisis sistem tata surya, rotasi dan revolusi bumi, rotasi dan revolusi bulan, serta dampaknya bagi kehidupan di bumi tepatnya pada indikator 3.11 .7 rotasi dan revolusi bumi, 3.11.8 rotasi dan revolusi bulan, 3.11.9 peristiwa akibat otasi dan revolusi bumi Ayat yang memuat tema tersebut pada diantaranya QS. Adz-Dzariyat: 7 ; QS. Al-Anbiya': 33 ; Yasin: 40 QS.Yasin: 38 ; QS. Shaffat: 5 ; QS. Yunus: 5 QS. Yasin: 39; QS.Syams: 1-2 ; QS. Az-Zumar: 5 ; QS. Al-Naml: 88.

Tahap Ketiga menjadikan Al-Quran sebagai pengawal dari setiap kerja sains. Al-Quran bukan sekedar menjadi pelengkap, tetapi sumber rujukan utama agar supaya menjadi lebih terarah dan mempunyai tujuan yang mengandungi banyak manfaat. Melalui tabel 2 dijelaskan ayat yang menjadi rujukan utama, sebagai penghantar sebelum memasuki pembelajaran. Dapat disampaikan pada diskusi pada awal pembelajaran.

Tabel 2 Integrasi Al-Quran dengan IPA Kompetensi Dasar 3.1

\begin{tabular}{|c|c|}
\hline bumi 3.11 .7 Rotasi dan revolusi & Aya \\
\hline $\begin{array}{l}\text { - Rotasi Bumi berputar } \\
\text { mengitari garis khayal yang } \\
\text { disebut sumbu atau poros. } \\
\text { - Sekali berotasi } \\
\text { membutuhkan waktu 24 } \\
\text { jam atau disebut satu hari. } \\
\text { Revolusi Bumi mengitari } \\
\text { Matahari pada garis edar } \\
\text { yang teratur yang disebut } \\
\text { orbit. } \\
\text { Satu kali putaran, lamanya } \\
3651 / 4 \text { hari atau satu } \\
\text { tahun. Waktu untuk } \\
\text { berevolusi ini disebut kala } \\
\text { revolusi }\end{array}$ & 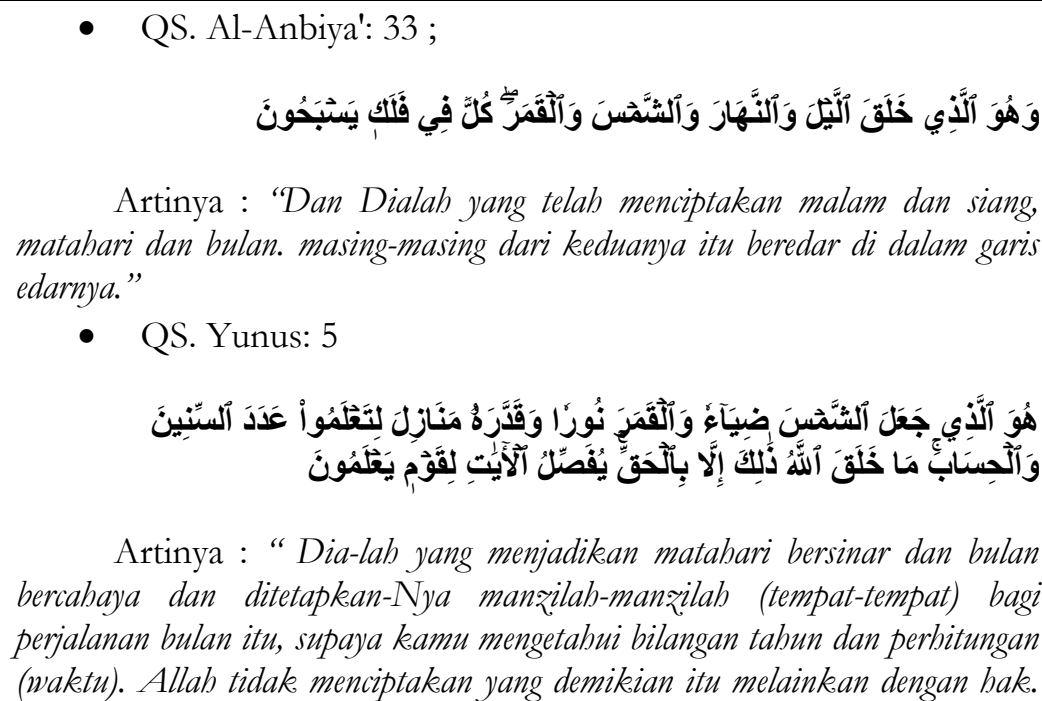 \\
\hline
\end{tabular}




\begin{tabular}{|c|c|}
\hline & $\begin{array}{l}\text { Dia menjelaskan tanda-tanda (kebesaran-Nya) kepada orang-orang yang } \\
\text { mengetabui." }\end{array}$ \\
\hline $\begin{array}{lll} & 3.11 .8 \text { rotasi dan revolusi } \\
\text { dlan } & & \\
\end{array}$ & Ayat Al-Quran \\
\hline $\begin{array}{l}\text { - Bulan berputar pada } \\
\text { porosnya atau berotasi. } \\
\text { Waktu yang diperlukan } \\
\text { Bulan untuk melakukan } \\
\text { satu kali rotasi sama } \\
\text { dengan waktu yang } \\
\text { diperlukan Bulan untuk } \\
\text { berevolusi. Yaitu 29 hari } \\
\text { hingga 30 hari. } \\
\text { Revolusi Bulan : Bulan } \\
\text { bergerak mengelilingi } \\
\text { Bumi. } \\
\text { Bulan akan tampak } \\
\text { berubah-ubah jika dilihat } \\
\text { dari Bumi yang disebut } \\
\text { dengan fase Bulan. } \\
\text { Gaya gravitasi Bulan } \\
\text { terhadap Bumi } \\
\text { mengakibatkan terjadinya } \\
\text { pasang surut air laut. }\end{array}$ & 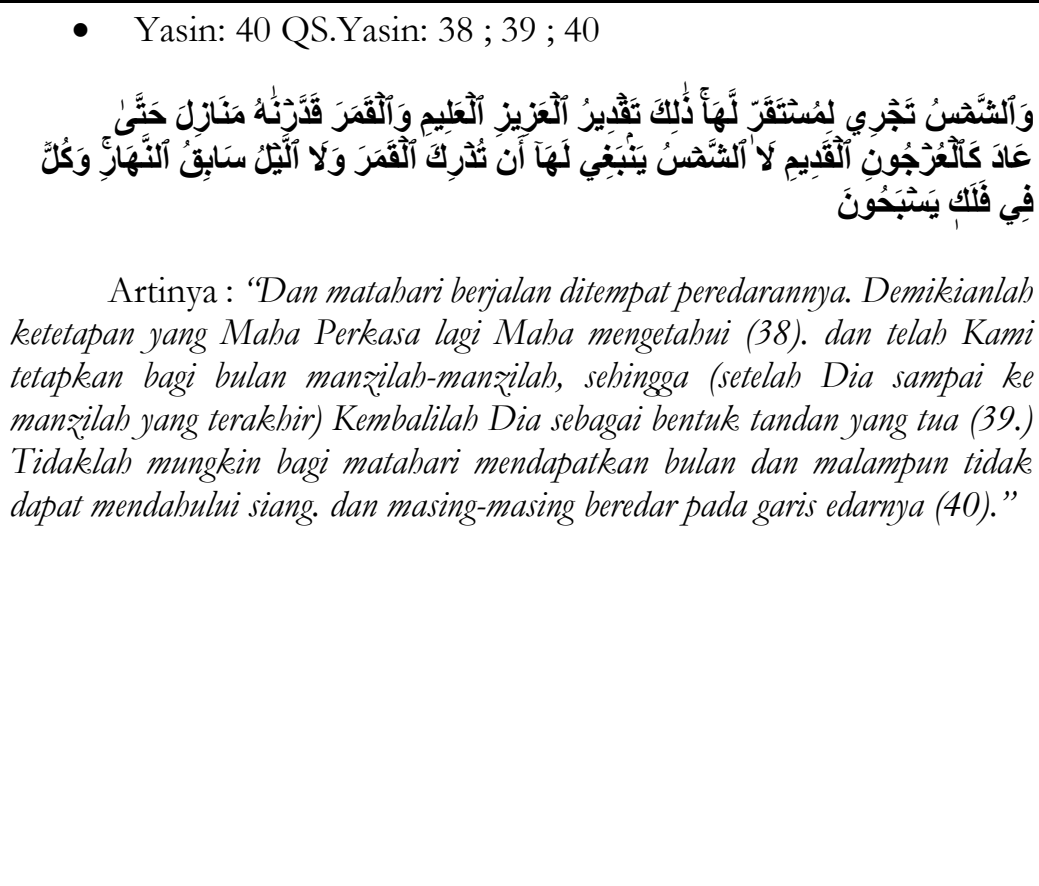 \\
\hline
\end{tabular}

Dia menjelaskan tanda-tanda (kebesaran-Nya) kepada orang-orang yang

3.11.9 Peristiwa akibat rotasi Ayat Al-Quran

dan revolusi bulan

- Akibat lain dari rotasi Bumi adalah sebagai berikut.

1. Gerak semu harian Matahari.

2. Perbedaan waktu.

3. Pembelokan arah angin.

4. Pembelokan arah arus laut.

- Akibat dari revolusi Bumi sebagai berikut.

1. Terjadinya gerak semu tahunan matahari. Perbedaan lamanya siang dan malam.

2. Pergantian musim.
QS. Az-Zumar: 5 ;

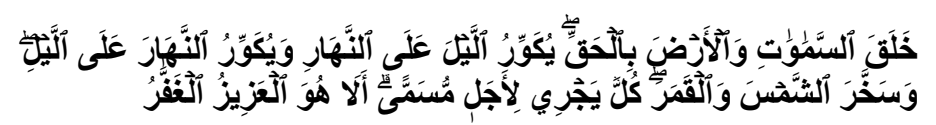

Artinya : "Dia menciptakan langit dan bumi dengan (tujuan) yang benar; Dia menutupkean malam atas siang dan menutupkean siang atas malam dan menundukkean matabari dan bulan, masing-masing berjalan menurut waktu yang ditentukan. ingatlah Dialah yang Maha Perkasa lagi Maha Pengampun.(5)" 
Diantara tanda-tanda kekuasaan Allah adalah adanya siang dan malam yang sangat menakjubkan dan memukau. Dia (Allah) telah menjadikan siang agar manusia, hewan, dan tumbuhan bisa mengusahakan kehidupannya dan perbuatan-perbuatan lain untuk kebaikan dan kesejahteraan, dan kelangsungan hidupnya. Allah juga menjadikan malam sebagai tempat istirahat, dan alam menjadi tenang. Hewan-hewan masuk dalam tempatnya masing-masing atau sarangnya. Setiap jiwa beristirahat dari rasa capek atau lelah hingga siap menjalani kehidupannya kembali keesokan harinya.

Pemahaman mengenai materi sistem tata surya, rotasi dan revolusi bumi, rotasi dan revolusi bulan, serta dampaknya bagi kehidupan di bumi dapat dikembangkan di masyarakat. Pengetahuan faktual dapat digunakan membantu orang lain. Pemahaman ini mendasari penentuan awal dan akhir bulan yang dapat digunakan penentuan tanggal 1 Ramadhan sebagai penenda dimulainya puasa Ramadhan, penentuan 1 Syawwal sebagai penentuan Hari Raya Idul Fitri, penentuan waktu Sholat dll. Pada rumusan kompetensi sikap sosial "Menunjukkan perilaku jujur, disiplin, tanggung jawab, peduli (toleransi, gotong royong), santun, dan percaya diri, dalam berinteraksi secara efektif dengan lingkungan sosial dan alam dalam jangkauan pergaulan dan keberadaannya". Hal ini merupakan bentuk nilai shalih dari santri Pesantren.

Nilai akram berkaitan dengan tauhid atau keimanan, pengetahuan tentang betapa besar kuasa Allah Yang Maha Pencipta dan mampu menjalankan semua sistem yang ada di sistem tata surya meningkatkan tingkat keimanan dan memperkuat ibadahnya ikhlas hanya karena Allah. Sesuai dengan rumusan kompetensi sikap spiritual yaitu "Menghargai dan menghayati ajaran agama yang dianutnya".

\section{KESIMPULAN}

Pembalajaran IPA terintegrasi Al-Quran dan nilai-nilai pesantren merupakan upaya islamisasi sains yang digunakan sebagai kurikulum pembelajaran di tingkat SMP/MTs. Bertujuan menghilangkan dikotomi adanya ilmu umum dan ilmu agama, menciptakan generasi yang cakap secara kognitif, spiritual dan sosial.

Seluruh KD IPA SMP/MTs Kelas VII yang dianalisis dengan Ayat Al-Quran menunjukkan potensi adanya integrasi antara keduanya. Niali-nilai pesantren berupa Shalih dan akram dapat diintegrasikan kedalam pembelajaran. Shalih dapat dimasukkan dalam kompetensi sosial meliputi kebermanfaatan terhadap masyarakat dan akram berupa kompetensi spiritual menghargai dan menghayati ajaran agama yang dianutnya.

Model integrasi yang penulis kembangkan ini terbatas pada KD kelas VII selanjutnya dapat dikembangkan lebih lanjut pada kelas VIII dan IX maupun pada tingkat SMA/MA dan masyarakat umum. Perlu adanya kerjasama antar berbagai fihak agar Pembalajaran IPA terintegrasi Al-Quran dan nilai-nilai pesantren dapat dimanfaatkan secara luas oleh berbagai kalangan..

\section{DAFTAR PUSTAKA}

Alimuddin. (2014). Penilaian dalam kurikulum 2013. Seminar NAsional Pendidikan Karakter.

Arifuddin. (2015). Konsep Integrasi Ilmu Dalam Pandangan Ismail Raji Al-Faruqi. Konsep Integrasi Ilmu Syamil F. Nashori, Membangun Paradigma Psikologi Islami.

Barizi, A. (2011). Pendidikan integratif: Akar tradisi dan integrasi keilmuan pendidikan Islam. UINMaliki Press.

Harahap, A. (2018). INTEGRASI ALQURAN DAN MATERI PEMBELAJARAN KURIKULUM SAINS PADA TINGKAT SEKOLAH DI INDONESIA: LANGKAH MENUJU KURIKULUM SAINS BERBASIS ALQURAN. JURNAL PENELITLAN $M E D A N A G A M A$, 9(1), 21-46.

Hsieh, H. F., \& Shannon, S. E. (2005). Three approaches to qualitative content analysis. Qualitative Health Research. https://doi.org/10.1177/1049732305276 687

Hudson, S. (2015). Effective Teaching Methods. Journal of Instructional Research. https://doi.org/10.9743/jir.2015.12

Idrus Hariri, A., \& Mulyani, A. (2016). PENERAPAN PEMBELAJARAN BERBASIS SAINS BUDAYA LOKAL 
NGASEUP PADA KONSEP SISTEM REPRODUKSI MANUSIA UNTUK MENINGKATKAN KETERAMPILAN BERPIKIR KRITIS SISWA KELAS XI SMAN 1 MAJA. Jurnal Sains Dan Pendidikan Sains Scientiae Educatia.

Jung, H., \& Choi, E. (2016). The importance of indirect teaching behaviour and its educational effects in physical education. Physical Education and Sport Pedagogy. https://doi.org/10.1080/17408989.2014. 923990

Jung, Y., \& Lee, J. (2018). Learning Engagement and Persistence in Massive Open Online Courses (MOOCS). Computers and Education.

https://doi.org/10.1016/j.compedu.2018 .02 .013

Khoirudin, A. (2017). Sains Islam Berbasis Nalar Ayat-ayat Semesta. At-Ta'dib. https://doi.org/10.21111/attadib.v12i1.883

Latifah, S., \& Ratnasari, R. (2016). Pengembangan Modul IPA Terpadu Terintegrasi Ayat-Ayat Al-Qur'an pada Materi Tata Surya. Jurnal Penelitian Pembelajaran Fisika. https://doi.org/10.26877/jp2f.v7i1.1150

Mahfudh, S. (2007). Nuansa Fiqib Sosial. Yogyakarta: LkiS.

Maxwell, J. A., \& Reybold, L. E. (2015). Qualitative Research. In International Encyclopedia of the Social \& Behavioral Sciences: Second Edition. https://doi.org/10.1016/B978-0-08097086-8.10558-6

Mengel, F., Sauermann, J., \& Zölitz, U. (2019). Gender bias in teaching evaluations. Journal of the European Economic Association. https://doi.org/10.1093/jeea/jvx057
Novitasari, R., Nasirun, M., \& D., D. (2019). MENINGKATKAN KEMAMPUAN MOTORIK KASAR ANAK MELALUI BERMAIN DENGAN MEDIA HULAHOOP PADA ANAK KELOMPOK B PAUD ALSYAFAQOH KABUPATEN REJANG LEBONG. Jurnal Ilmiah POTENSLA, 4(1), 6-12. https://doi.org/10.33369/jip.4.1.612

Nurochim, N. (2016). Sekolah Berbasis Pesantren Sebagai Salah Satu Model Pendidikan Islam Dalam Konsepsi Perubahan Sosial. Al-Tahrir: Jurnal Pemikiran Islam, 16(1), 69. https://doi.org/10.21154/altahrir.v16i1.320

Parker, I., \& Parker, I. (2020). Qualitative. In Psychology through Critical Auto-Ethnography. https://doi.org/10.4324/9780429325687 $-24$

Qu, S. Q., \& Dumay, J. (2011). The qualitative research interview. Qualitative Research in Accounting and Management. https://doi.org/10.1108/1176609111116 2070

Selviani, I. (2019). Pengembangan Modul Biologi Problem Based Learning Untuk Meningkatkan Kemampuan Berpikir Kritis Peserta Didik SMA. IJIS Edu: Indonesian Journal of Integrated Science Education, 1(2). https://doi.org/10.29300/ijisedu.v1i2.20 32

Skaalvik, E. M., \& Skaalvik, S. (2011). Teacher job satisfaction and motivation to leave the teaching profession: Relations with school context, feeling of belonging, and emotional exhaustion. Teaching and Teacher Education. https://doi.org/10.1016/j.tate.2011.04.00 1 
Sudarsana, I. K. (2018). Membentuk Karakter Anak Sebagai Generasi Penerus Bangsa Melalui Pendidikan Anak Usia Dini. Purwadita: Jurnal Agama Dan Budaya, 1(1), 41-48.

Sudiarti, T., Delilah, G. G. A., \& Aziz, R. (2018). Besi dalam Qur'an dan Sains Kimia (Analisis Teoritis dan Praktis Mengenai Besi dan Upaya Mengatasi Korosi pada Besi. Al-Kimiya. https://doi.org/10.15575/ak.v5i1.3720

Tiswarni, T. (2019). USAHA KEPALA SEKOLAH DALAM MENINGKATKAN DISIPLIN KERJA GURU (Studi Deskriptif Kualitatif di SMP N 1 Argamakmur Kabupaten Bengkulu utara). At-Ta'lim: Media Informasi Pendidikan Islam, 18(1), 261. https://doi.org/10.29300/attalim.v18i1.1 650

Williamson, K., Given, L. M., \& Scifleet, P. (2018). Qualitative data analysis. In Research Methods: Information, Systems, and Contexts: $\quad$ Second Edition. https://doi.org/10.1016/B978-0-08102220-7.00019-4

Wong, V. W., Ruble, L. A., Yu, Y., \& McGrew, J. H. (2017). Too stressed to teach? Teaching quality, student engagement, and IEP outcomes. Exceptional Children. https://doi.org/10.1177/0014402917690 729

Yusuf, M. Y. (2015). PESANTREN SAINS: EPISTEMOLOGY OF ISLAMIC SCIENCE IN TEACHING SYSTEM. Walisongo: Jurnal Penelitian Sosial Keagamaan, 23(2), 283. https://doi.org/10.21580/ws.23.2.280 